\title{
Tourette syndrome research highlights from 2018 [version 1;
}

\section{peer review: 2 approved]}

\author{
Olivia Rose (iD1, Andreas Hartmann (D)2, Yulia Worbe², Jeremiah M. Scharf3, \\ Kevin J. Black (iD) 1,4 \\ ${ }^{1}$ Department of Neuroscience, Washington University School of Medicine, St. Louis, MO, 63110, USA \\ ${ }^{2}$ Sorbonne University, National Reference Centre for Tourette Disorder, Pitié-Salpêtrière Hospital, Paris, France \\ ${ }^{3}$ Psychiatric and Neurodevelopmental Genetics Unit, Massachusetts General Hospital, Boston, Massachusetts, USA \\ ${ }^{4}$ Psychiatry, Neurology, and Radiology, Washington University School of Medicine, St. Louis, MO, 63110, USA
}

V1 First published: $01 \mathrm{Jul}$ 2019, 8:988

https://doi.org/10.12688/f1000research.19542.1

Latest published: $01 \mathrm{Jul}$ 2019, 8:988

https://doi.org/10.12688/f1000research.19542.1

\section{Abstract}

This is the fifth yearly article in the Tourette Syndrome Research Highlights series, summarizing research from 2018 relevant to Tourette syndrome and other tic disorders. The authors briefly summarize reports they consider most important or interesting. The highlights from 2019 article is being drafted on the Authorea online authoring platform, and readers are encouraged to add references or give feedback on our selections using the comments feature on that page. After the calendar year ends, the article is submitted as the annual update for the Tics collection on F1000Research.

\section{Keywords}

Tourette syndrome, tic disorders, review, natural history, etiology, pathophysiology

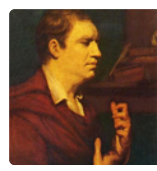

This article is included in the Tics collection.

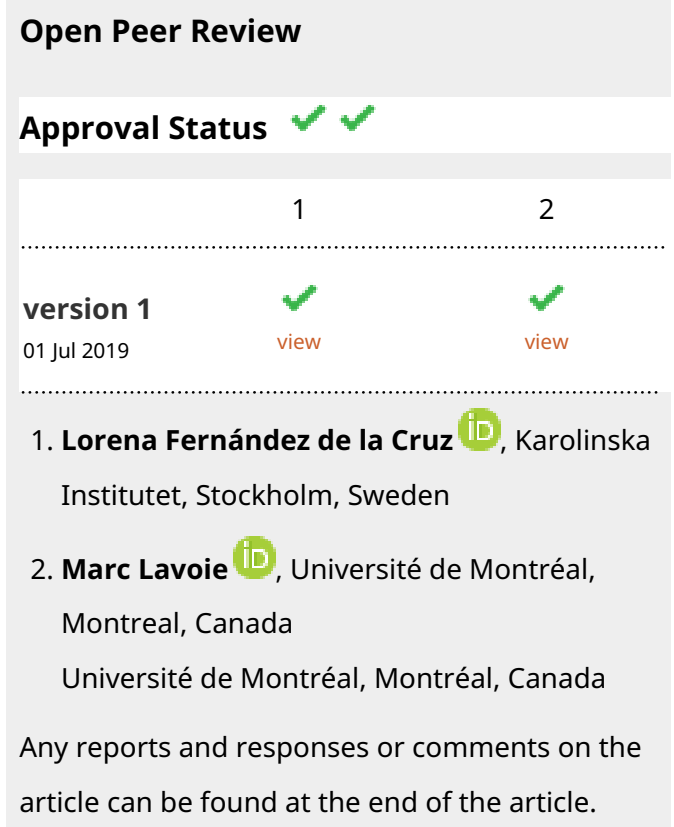


Corresponding author: Kevin J. Black (kevin@wustl.edu)

Author roles: Rose 0: Investigation, Writing - Original Draft Preparation, Writing - Review \& Editing; Hartmann A: Investigation, Writing - Original Draft Preparation, Writing - Review \& Editing; Worbe Y: Writing - Review \& Editing; Scharf JM: Investigation, Writing Original Draft Preparation, Writing - Review \& Editing; Black KJ: Conceptualization, Investigation, Writing - Original Draft Preparation, Writing - Review \& Editing

Competing interests: KJB participated in clinical trials supported by Neurocrine Biosciences and Acadia Pharmaceuticals.

Grant information: This work was supported in part by the U.S. National Institutes of Health (NIH) [R01 MH104030]. The funders had no role in study design, data collection and analysis, decision to publish, or preparation of the manuscript.

Copyright: @ 2019 Rose $O$ et al. This is an open access article distributed under the terms of the Creative Commons Attribution License, which permits unrestricted use, distribution, and reproduction in any medium, provided the original work is properly cited.

How to cite this article: Rose $O$, Hartmann A, Worbe $Y$ et al. Tourette syndrome research highlights from 2018 [version 1; peer review: 2 approved] F1000Research 2019, 8:988 https://doi.org/10.12688/f1000research.19542.1

First published: $01 \mathrm{Jul}$ 2019, 8:988 https://doi.org/10.12688/f1000research.19542.1 


\section{Introduction}

This article is meant to disseminate recent scientific progress on Gilles de la Tourette Syndrome (TS).

\section{Methods}

We searched PubMed from time to time during 2018 using the search strategy "("Tic Disorders" $[\mathrm{MeSH}]$ OR Tourette NOT Tourette[AU]) AND 2018[PDAT] NOT 1950:2017[PDAT]”. On 20 May 2019 this search returned 192 citations. Colleagues also recommended articles, and we attended selected medical conferences. We selected material for this review subjectively, guided by our judgment of possible future impact on the field.

\section{Results}

Phenomenology and natural history

Epidemiology. All chronic tic disorders (CTD) begin at some point in time; it has not been clear which children with a recent-onset tic disorder would go on to develop a chronic tic disorder, and which would permanently remit. Kim and colleagues report on 43 children initially studied an average of 3 months after tic onset, of whom 39 returned at the 12-month anniversary of their first tic (Kim et al., 2018a; Kim et al., 2019). Not surprisingly, symptoms had generally improved at the 12-month mark. Surprisingly, however, every child still had tics, some apparent only when observed alone (by video). Baseline predictors of more severe tics at outcome included baseline tic severity, subsyndromal autism spectrum symptoms, three or more phonic tics, or an anxiety disorder. These results suggest that the current 12-month cutoff for chronicity may be arbitrary, and that mild tics that are not evident on a typical brief examination may be much more common than previously known.

Lowe and colleagues performed a very long interval followup study on TS, assessing tic severity, quality of life, and psychosocial function (Lowe et al., 2019). Of 150 surveys mailed to patients seen 25-32 years ago, 45 were returned (30\%). $79 \%$ reported still having at least some tics, $40 \%$ reported some level of social impairment, and 20\% were either unemployed, disabled or financially supported by family. However, the great majority of patients had improved in terms of tics and were doing well in other areas of their lives. Tics are 4-6 times more common in children with attention deficit hyperactivity disorder (ADHD) than in those without, and tics add to clinical problems and reduced quality of life (Poh et al., 2018).

Sensory phenomena and premonitory urges. Jakubovski et al. administered an online survey to characterize premonitory urges in individuals with TS (Jakubovski et al., 2018). The authors found that premonitory urges occurred in $73 \%$ of their sample, and that premonitory urge was more likely to occur with complex tics (78.6\%) over simple tics (68.9\%). Premonitory urges tended to localize in the same body area as the tics themselves, contrary to previous, smaller reports.

Interoception is interesting as it shares features with sensory phenomena in TS (Khalsa et al., 2018). A derived measure of interoception predicts tic severity and premonitory sensations in TS; the authors propose their results suggest "a heightened higher-order sensitivity to bodily sensations in TS, relative to a noisier perceptual representation of afferent bodily signals" (Rae et al., 2019).

Impaired olfactory function, but normal peripheral detection of olfactory stimuli, was demonstrated in TS (Kronenbuerger et al., 2018). Subjects with TS $(\mathrm{n}=28)$ did not differ in odor detection threshold, but did present with impairments in both odor discrimination and odor identification. There was no significant difference in tobacco usage between the groups. $25 \%$ percent of subjects with TS met criteria for functional anosmia, compared to $7 \%$ of controls. This suggests that alterations in olfactory phenomena likely occur during higher-order processing, rather than during peripheral detection, in people with TS. This observation is consistent with previous similar conclusions about tactile sensory function in TS.

Other. Weingarden et al. report that self-esteem is decreased in adults with TS and CTD $(\mathrm{n}=122)$ (Weingarden et al., 2018). This, however, is less related to tics or tic severity but rather related to other psychiatric symptoms. When treating these patients, self-esteem was improved more by Comprehensive Behavioral Intervention for Tics (CBIT) than by psychoeducation and supportive therapy (PST), which seems plausible. It would be interesting to replicate the same study in children and adolescents. A review also examines the concept of selfesteem in TS and CTD, drawing a similar conclusion: that poor self-esteem appears more strongly related to psychiatric comorbidities than to tic severity, and, unsurprisingly, affects quality of life (Silvestri et al., 2018).

TS phenotypes were investigated in 174 children and adolescents in French university clinic (Cravedi et al., 2018). Three clusters were identified. One of them corresponded to a tic-only phenotype ('pure' TS) whereas another cluster included learning and intellectual disabilities, ASD, and ADHD. The third cluster corresponded to an ADHD profile with rather high intelligence and handwriting problems due to tics. Therapeutic implications are discussed.

A survey of almost 700 parents, about half with tics, found that children with current or past tics slept an average of 1.5 hours less per night than control children (Ricketts et al., 2017). This result supports clinical experience and underlines both the impact of tic disorders on quality of life and a potential avenue for treatment. In children and adolescents with obsessive-compulsive disorder (OCD), religious symptoms were not associated with various clinical variables including outcome (Wu et al., 2018). This result suggests that scrupulosity and similar symptoms in children with TS can be expected to improve just as much as other OCD symptoms with appropriate treatment.

While restricted food preferences have been well-documented in autism spectrum disorder (ASD), Smith et al. found similar patterns of food sensitivity in 30 children with TS. 25 subjects had comorbid conditions, though none in the sample had been diagnosed with ASD. Caregivers of children with TS reported 
their children having greater sensory sensitivities to food, greater food selectivity, and decreased consumption of dairy, vegetables, and fruit (Robbins, 2018; Smith et al., 2019).

Severe neck tics led to a vertebral artery dissection (Aydin et al., 2018), a reminder that tics are not always benign. Another case report describes closed head trauma due to head banging in a 15-year-old, with important sequelae (Fasano \& Galluccio, 2018). These reports underline the need for rapid and aggressive tic management in some patients.

\section{Etiology}

Genetics. There have been a number of advances in TS genetics over the past year, each arising from large-scale, multiconsortia collaborative efforts. Building off of two articles published the previous year reporting an increased genomewide significant burden of rare, gene-disrupting mutations in 5-10\% of TS patients (Huang et al., 2017; Willsey et al., 2017), Wang and colleagues reported the largest study of rare, de novo gene-disrupting mutations in TS to date (Wang et al., 2018). After first demonstrating that this class of mutations (de novo likely gene-damaging coding mutations and gene-disrupting copy-number variants/deletions) were specifically enriched in TS patients without a family history of a tic disorder (two unaffected parents) compared to patients with a positive parental history of tics, they conducted a combined de novo analysis of 802 parent-proband trios that identified a new high confidence TS susceptibility gene CELSR3, as well as an observation that the group potentially causative new mutations were more likely to affect genes involved in cell polarity. In parallel, Yu and colleagues reported the latest TS genome-wide association study (GWAS) of 4819 cases and 9488 controls, in which they identified one strong candidate TS gene (FLT3), and confirmed prior findings that a large proportion of TS heritability can be attributed to the aggregated effects of common genetic risk variants spread across the genome (Yu et al., 2019). They subsequently demonstrated that, in subjects with a family history of a tic disorder (TS or chronic tics), aggregated genome-wide TS polygenic risk scores (PRS) were significantly associated with lifetime worst-ever tic severity scores. In addition, both $\mathrm{Yu}$ and colleagues and Abdulkadir and colleagues used the TS GWAS polygenic risk scores to probe two independent population-based GWAS samples and found that individuals with non-TS tic disorders also have elevated TS polygenic risk compared to unaffected controls, albeit to a lesser degree than individuals with TS (Abdulkadir et al., 2019); (Yu et al., 2019). These two findings therefore confirm at the genetic level that TS and other tic disorders likely exist along a continuous spectrum as opposed to their current classification as distinct diagnostic entities. Lastly, Mufford and colleagues used the same TS GWAS PRS to probe imaging genetic data of subcortical brain volumes in the ENIGMA (Enhancing Neuro Imaging Genetics Through Meta Analysis) consortium, essentially tying the genetics of TS to the genetics of brain volumes (Mufford et al., 2018).

Separately, a huge study of shared GWAS data from over a million people with various neurologic and psychiatric disorders revealed that TS shares common variant genetic risk with OCD, major depression, and, unexpectedly, with migraine, especially migraine with aura (Brainstorm Consortium et al., 2018).

Environmental risk factors. A large, full-population study from Sweden studied all singleton births in Sweden over a 30-year period, using siblings as controls (Brander et al., 2018). It found that "impaired fetal growth, preterm birth, breech presentation and cesarean section were associated with a higher risk of" TS or CTD. The risks were dose-dependent, with hazard ratios rising from 1.41 for one adverse perinatal event to 2.42 for five or more such events. This report is important due to its careful design, sample size and implications. It confirms previous indications that not all of the risk for TS is inherited, and points specifically to intrauterine and birth insults as contributing to that risk.

A nationwide study from Denmark showed that children treated with an antibiotic or admitted to a hospital for an infection had a significantly higher risk of a later diagnosis of any psychiatric illness (Köhler-Forsberg et al., 2019). Interestingly, the highest risk for antibiotic use was for tic disorders, followed by OCD. (Hospitalization risk was higher for intellectual disability, though tic disorders were next highest.) The association does not prove that infections cause TS; e.g., patients destined to develop TS, or their parents, may be more likely to seek help for infections. Nevertheless, the association is interesting and deserves follow-up.

\section{Pathophysiology}

Animal models. Nespoli et al. (2018) found that dopaminergic imbalance in the dorsal striatum induced a Tourette's-like phenotype in a rodent model. Administration of quinpirole, a selective D2/D3 receptor agonist, in juvenile rats with lesions to striatal projection neurons produced movements suggestive of both simple and complex tics in the neck, limbs, and mouth. A modified Yale Global Tic Severity Scale (YGTSS) was created to comprehensively score tic-like movements based on frequency, complexity, and severity of impairment. Immunohistochemical analyses revealed significantly decreased D1 receptor RNA expression at the lesion site, consistent with the decreased striatal D1 receptor expression seen in a human post-mortem study of TS (Lennington et al., 2016). The dopaminergic imbalance induced by decreased striatal D1 receptor activity, coupled with increased D2 receptor activity, may be relevant to TS.

Electrophysiology. Eight awake TS patients undergoing DBS electrode implantation had recordings of individual cells of the external and internal globus pallidus (GP) (Israelashvili et al., 2017). Some cells in each division of the GP showed transient changes in firing rates associated with tics.

Neuroimaging studies. Mahone et al. utilized 7T spectroscopy to investigate glutamate and GABA concentrations in children with TS. Findings included increased premotor area glutamate concentrations in TS, which also positively correlated with inhibitory control (Mahone et al., 2018). 
White matter tractography in children and adolescents with TS has not been well characterized, as previous studies utilizing diffusion tensor imaging (DTI) have primarily sampled from adult TS patients. Sigurdsson et al. examined white matter connectivity and water diffusivity in youth with TS, and report widespread decreases in axial diffusivity (Sigurdsson et al., 2018). The authors excluded subjects with high head motion, but even small head movements can affect DTI estimates (Baum et al., 2018).

In an event-related Functional magnetic resonance imaging (fMRI) study of 15 adults with TS, successful tic suppression correlated with increased activation in dorsal anterior cingulate cortex (van der Salm et al., 2018). 22 healthy controls performed a blink suppression task. During voluntary blink suppression, results yielded increased activation in ventrolateral prefrontal cortex, supplementary motor area, and cingulate motor area. These results suggest limbic system control of tic suppression, in contrast to sensorimotor system engagement in blink suppression. It would be an interesting follow-up to investigate whether suppression of normal blinks in TS patients displays the same patterns of activation seen in healthy controls, or reflects impairments in sensorimotor or limbic system control.

21 adults with TS and 21 healthy controls performed an fMRI study during perception of neutral or angry faces (Rae et al., 2018). In TS, insula functional connectivity (fc) was increased with pre-supplementary motor area (SMA), premotor cortex, primary motor cortex and putamen. Insula fc with globus pallidus and thalamus varied with tic severity, while insula-SMA fc varied with premonitory sensations. These results strengthen the evidence that insula and SMA are involved with premonitory urges and tics.

Pharmacological studies. Maia \& Conceição (2018) elaborate on their theory of how dopamine may relate to tics in TS. Hienert et al. (2018) provide a meta-analysis of positron emission tomography (PET) and single-photon emission computed tomography (SPECT) studies in TS measuring the dopamine transporter (DAT) or $\mathrm{D}_{2}$-like dopamine receptors; neither showed conclusive differences in patients, but sample sizes and methodological limitations may explain the negative results.

Clinical and neuropsychological studies. The potential role that autoimmunity may play in TS pathology has long been controversial. A large-scale population study from a Swedish birth cohort assessed the risk factors of 40 different autoimmune diseases in individuals with TS/CTD and/or OCD, as well as family members with varying degrees of relatedness (Mataix-Cols et al., 2018). TS/CTD was associated with a $36 \%$ increase in likelihood of having any autoimmune disease, compared with matched population controls. Additionally, the mothers of subjects diagnosed with TS/CTD were $40 \%$ more likely to have an autoimmune disease; full siblings of individuals with TS/CTD carried a $17 \%$ increase in risk. The authors note that it is undetermined if these numbers support the hypothesized immunological component of TS/CTD, or instead reflect a selection bias for those already receiving medical care.
A research consortium in Germany has recently proposed that tics may correspond to altered perception-action binding (Beste \& Münchau, 2018). Petruo et al. (2018) now provide a first experimental demonstration in 35 adolescents with TS and 39 healthy controls using a Go/No-go task and subsequent electroencephalography (EEG) analysis, providing support for the idea that stimulus-action binding is stronger in patients with TS, and that "unbinding" may thus represent a useful therapeutic venue.

Inhibitory control in TS has been assessed in a myriad of different ways, with conflicting results. For instance, Mancini et al. (2018) report abnormal inhibitory function in patients with OCD, but no deficits in the TS group. Similarly, Stenner et al. (2018) performed a clever study of a form of automatic motor inhibition. Exposure to a subliminal stimulus at an appropriate time prior to a supraliminal movement cue inhibits movement, a phenomenon called the negative compatibility effect (NCE). Here, 21 adults with TS and 21 tic-free controls performed similarly, suggesting that NCE is another form of experimental motor inhibition that appears normal in TS.

By contrast, the role of abnormal habit-learning has been posited as a cognitive marker of TS. It is yet unclear if tics would result from increased habit-learning, deficits in unlearning maladaptive behaviors, or a combination of both. Shephard et al. (2018) investigated implicit sequence learning in youth with TS with or without ADHD compared to tic-free youth with or without ADHD. Subjects with ADHD demonstrated impaired learning of a motor sequence learning task, while subjects with TS had mildly enhanced learning. However, they found evidence of "hyper-learning," in which subjects with TS had difficulty in unlearning the motor sequence task. Similarly, Kim et al. (2018b) demonstrated slower unlearning (forgetting) of a visuomotor task in children and adolescents with TS. The role that impaired habit unlearning may play in TS warrants further investigation.

Adaptive functioning, a person's ability to function and organize themselves in daily life, has not been well-characterized in TS. Taylor et al. found that, in a TS sample, deficits in adaptive functioning were mostly driven by impaired executive function (Taylor et al., 2018). ADHD and two or more comorbid conditions were associated with decreased adaptive functioning. More than half of the variance in this study was explained by deficits in executive function, rather than tics themselves. These results suggest that aggressive treatment of ADHD and comorbid diagnoses may be important in clinical management of TS.

\section{Treatment}

Psychological interventions. Group-based psychotherapeutic interventions for tics bear the promise of reduced costs and easier access to appropriate care, and several recent reports address this treatment option. One recent paper investigated the long term effects of group therapy on tic severity, quality of life and school attendance in 28 children with TS 12 months after completing habit reversal training (HRT) training or education 
(a follow up to the 2016 study (Yates et al., 2016)). This study demonstrated positive effects in the long run but apparently without significant differences between both groups (Dabrowski et al., 2018). A Danish study investigated a combined exposure and response prevention (ERP)/HRT protocol comparing group with individual sessions $(n=27$ per group, $n=54$ total). The efficacy on decreasing tic severity was similar in both treatment arms (Nissen et al., 2019). Traditionally, ERP sessions (as compared to HRT/cognitive behavioral intervention for tics (CBIT)) lasted for two hours, making them more difficult and expensive. In this study, session duration was shortened to one hour and shorter exposure was as effective, if not more, than the classic format (van de Griendt et al., 2018). In another potential method for wider behavior therapy accessibility, (Andrén et al., 2019) report preliminary results from a major study on therapist-supported, parent-guided, online behavior therapy for TS. Patients improved substantially (mean $75 \%$ with ERP, 55\% with HRT), and the improvement persisted up to 12 months later. The average therapist time was only 25 minutes per week.

Medication. Swedish treatment registries were searched to identify patterns of medication prescribing for almost 7000 patients with TS/CTD from 2005-2013 (Carulla-Roig et al., 2018). Among other interesting findings, ADHD drugs, antidepressants, and hypnotics/sedatives were all prescribed more often than antipsychotics, for which there is much stronger evidence of efficacy. Rizzo et al. (2018) provide the first direct comparison of pharmacotherapy with behavioral therapy in children and adolescents with TS / CTD. Both approaches were effective in reducing tics and improving quality of life; however, only pharmacotherapy was effective in reducing OC symptoms.

The D1 receptor antagonist ecopipam was compared to placebo in a double-blind, crossover, randomized controlled trial (RCT) in children and adolescents with TS (Gilbert et al., 2018). YGTSS total tic score (TTS) declined significantly more with the active drug. Another drug acting largely on dopamine, the VMAT2 inhibitor valbenazine, was tested in a phase IIb study in TS, but failed to meet the primary efficacy endpoint (Neurocrine Biosciences Inc., 2018).

Neurosurgery. A large-scale public database and registry for deep brain stimulation (DBS) Tourette syndrome has been established (Martinez-Ramirez et al., 2018). This report summarizes information on 185 Tourette patients from 10 countries. Mean improvement in total YGTSS score was $40 \%$ at 6 months after vs. before surgery, and $45 \%$ at 12 months. The difference between stimulation sites (centromedian nucleus (CM-Pf), anterior globus pallidus interna (GPi), posterior $\mathrm{GPi}$ ) was not statistically significant. About a third of patients had side effects, mostly related to stimulation not surgery. A large, collaborative group is using this database to investigate the optimal site for DBS via a 3D analysis (Johnson et al., 2018). DBS in children remains controversial. Coulombe et al. (2018) review available data on DBS in "children" (ages 12-21), and Smeets et al. (2018) discuss ethical considerations regarding DBS in TS patients under the age of 18 .

Other treatment. In a pilot study, Behler et al. administered bilateral cathodal transcranial direct current stimulation (tDCS) over motor cortex in three patients with TS. While one patient displayed a $35 \%$ improvement in tic severity, the other two subjects experienced worsening of symptoms. However, all three patients did report a decrease in negative affect, as well as a mild increase in positive affect (Behler et al., 2018).

\section{Tics, family and society}

Himle et al. (2018) review how tics can affect the family and vice versa. Two large studies have now demonstrated clearly how much TS can hinder school performance. The first is a large study, conducted by the CDC via telephone survey, from the US. The authors found that TS (specifically, when compared to children without TS both with and without other neuropsychiatric conditions) has negative consequences for school performance (Claussen et al., 2018). Subjects with moderate-to-severe TS ( $\mathrm{n}=97$ ), when compared to those with milder symptoms ( $n=203$ ), were significantly more likely to require an individualized education plan (IEP). Furthermore, the prevalence of co-morbid psychiatric illness in TS is quite high; $80 \%$ of subjects with TS had at least one co-morbid neuropsychiatric disorder, compared to $18 \%$ of subjects without TS. The second study is from the population registry in Sweden, demonstrating academic underachievement in TS/CTD across all educational levels (Pérez-Vigil et al., 2018). One limitation of this study is that it relies on those who are diagnosed by a physician, who we know are a proper subset of those with tics. One would not be surprised to learn that the factors that lead to care-seeking (like severity of symptoms, or other undiagnosed behavioral problems) may also themselves interfere with education. Commenting on this article, Hartmann and Delorme write, "Ticcing as such impairs attention, and attempts to supress tics at school or work makes things even worse. Teasing and bullying because of tics is a further contributing factor to attention problems. Thus, tics impair academic achievement in their own right, and comorbidities can only partially be blamed for this situation. ... TS and CTD are not harmless neurological conditions but profoundly affect a person's life trajectory (see also Mataix-Cols' work on suicide in TS (Fernández de la Cruz et al., 2017)). Take tics seriously!" (Hartmann \& Delorme, 2018).

\section{Additional reference sources}

Several useful review articles appeared during 2018 (Efron \& Dale, 2018; Ganos et al., 2018; Garnaat et al., 2018; Hartmann \& Worbe, 2018; Stern, 2018).

\section{Conclusions}

The literature on TS is increasing rapidly. Fortunately, studies with larger sample sizes are becoming more common. Several simple but important questions remain to be answered in TS, 
including the following: Why do tics tend to start at ages 5-10? Why are they more common in boys? Why do they tend to improve during sleep? Why do tics usually improve in early adulthood? How accurately can we predict outcome for an individual patient? Which patients need which treatments? Is secondary prevention possible? Hopefully future studies will address these and other important issues.
Grant information

This work was supported in part by the U.S. National Institutes of Health (NIH) [R01 MH104030].

The authors confirm that the funder had no role in study design, data collection and analysis, decision to publish, or preparation of the manuscript.
Abdulkadir M, Mathews CA, Scharf JM, et al.: Polygenic Risk Scores Derived From a Tourette Syndrome Genome-wide Association Study Predict Presence of Tics in the Avon Longitudinal Study of Parents and Children Cohort. Biol Psychiatry. 2019; 85(4): 298-304.

PubMed Abstract | Publisher Full Text | Free Full Text

Andrén $\mathrm{P}$, Aspvall K, Fernándezde la Cruz L, et al: Therapist-guided and parentguided internet-delivered behaviour therapy for paediatric Tourette's disorder: a pilot randomised controlled trial with long-term follow-up. BMJ Open. 2019; 9(2): e024685.

PubMed Abstract | Publisher Full Text | Free Full Text

Aydin O, Tasdemir H, Bilgici MC, et al.: Vertebral Artery Dissection Caused by Neck Tics. J Pediatr Neurol. 2018; 16(06): 408-410.

Publisher Full Text

Baum GL, Roalf DR, Cook PA, et al:: The impact of in-scanner head motion on structural connectivity derived from diffusion MRI. Neurolmage. 2018; 173: 275-286.

PubMed Abstract | Publisher Full Text | Free Full Text

Behler N, Leitner B, Mezger E, et al.: Cathodal tDCS Over Motor Cortex Does Not Improve Tourette Syndrome: Lessons Learned From a Case Series. Front Behav Neurosci. 2018; 12: 194

PubMed Abstract | Publisher Full Text | Free Full Text

Beste C, Münchau A: Tics and Tourette syndrome - surplus of actions rather than disorder? Mov Disord. 2018; 33(2): 238-242.

PubMed Abstract | Publisher Full Tex

Brainstorm Consortium, Anttila V, Bulik-Sullivan B, et al:: Analysis of shared heritability in common disorders of the brain. Science. 2018; 360(6395): pii: eaap8757.

PubMed Abstract | Publisher Full Text | Free Full Text

Brander G, Rydell M, Kuja-Halkola R, et al.: Perinatal risk factors in Tourette's and chronic tic disorders: a total population sibling comparison study. Mol Psychiatry. 2018; 23(5): 1189-1197.

PubMed Abstract | Publisher Full Text | Free Full Text

Carulla-Roig M, Isomura K, Pérez-Vigil A, et al:: Pharmacoepidemiology of

Tourette and Chronic Tic Disorders in Sweden 2005-2013. J Child Adolesc

Psychopharmacol. 2018; 28(9): 637-645.

PubMed Abstract | Publisher Full Text

Claussen AH, Bitsko RH, Holbrook JR, et al.: Impact of Tourette Syndrome on School Measures in a Nationally Representative Sample. J Dev Behav Pediatr. 2018; 39(4): 335-342.

PubMed Abstract | Free Full Text

Coulombe MA, Elkaim LM, Alotaibi NM, et al.: Deep brain stimulation for Gilles de la Tourette syndrome in children and youth: a meta-analysis with individual participant data. J Neurosurg Pediatr. 2018; 23(2): 236-246.

PubMed Abstract | Publisher Full Text

Cravedi E, Deniau E, Giannitelli M, et al.: Disentangling Tourette syndrome heterogeneity through hierarchical ascendant clustering. Dev Med Child Neurol. 2018; 60(9): 942-950.

PubMed Abstract | Publisher Full Text

Dabrowski J, King J, Edwards K, et al.: The Long-Term Effects of GroupBased Psychological Interventions for Children With Tourette Syndrome: A Randomized Controlled Trial. Behav Ther. 2018; 49(3): 331-343.

PubMed Abstract | Publisher Full Text

Efron D, Dale RC: Tics and Tourette syndrome. J Paediatr Child Health. 2018; 54(10): 1148-1153.

PubMed Abstract | Publisher Full Text

Fasano A, Galluccio V: Brain injury due to head banging in Tourette.

Parkinsonism Relat Disord. 2018; 49: 114-115.

PubMed Abstract | Publisher Full Text

Fernández de la Cruz L, Rydell M, Runeson B, et al.: Suicide in Tourette's and Chronic Tic Disorders. Biol Psychiatry. 2017; 82(2): 111-118.

PubMed Abstract | Publisher Full Tex

Ganos C, Rothwell J, Haggard P: Voluntary inhibitory motor control over involuntary tic movements. Mov Disord. 2018; 33(6): 937-946.

PubMed Abstract | Publisher Full Text
Garnaat SL, Conelea CA, McLaughlin NCR, et al.: Pediatric OCD in the era of RDoC. J Obsessive Compuls Relat Disord 2018.

Publisher Full Text

Gilbert DL, Murphy TK, Jankovic J, et al.: Ecopipam, a D1 receptor antagonist, for treatment of tourette syndrome in children: A randomized, placebo-controlled crossover study. Mov Disord. 2018; 33(8): 1272-1280.

PubMed Abstract | Publisher Full Text

Hartmann A, Delorme C: F1000Prime Recommendation of [Pérez-Vigil A et al., JAMA Neurol 2018 75(9): 1098-1105]. F1000Prime. 2018.

Publisher Full Text

Hartmann A, Worbe Y: Tourette syndrome: clinical spectrum, mechanisms and personalized treatments. Curr Opin Neurol. 2018; 31(4): 504-509.

PubMed Abstract

Hienert M, Gryglewski G, Stamenkovic M, et al:: Striatal dopaminergic alterations in Tourette's syndrome: a meta-analysis based on 16 PET and SPECT neuroimaging studies. Trans/ Psychiatry. 2018; 8(1): 143.

PubMed Abstract | Publisher Full Text | Free Full Text

Himle MB, Wellen BCM, Hayes LP: Family Issues Associated With Tics. In The Clinicians Guide to Treatment and Management of Youth with Tourette Syndrome and Tic Disorders. Elsevier, 2018; 301-325.

Publisher Full Text

Huang AY, Yu D, Davis LK, et al.: Rare Copy Number Variants in NRXN1 and CNTN6 Increase Risk for Tourette Syndrome. Neuron. 2017; 94(6): 1101-1111.e7. PubMed Abstract | Publisher Full Text | Free Full Text

Israelashvili M, Smeets AYJM, Bronfeld M, et al.: Tonic and phasic changes in anteromedial globus pallidus activity in Tourette syndrome. Mov Disord. 2017; 32(7): 1091-1096.

PubMed Abstract | Publisher Full Text

Jakubovski E, Essing J, Psithakis N, et al.: Premonitory urges revisited: new insights into the location and quality of premonitory urges. 2018.

Publisher Full Text

Johnson K, Servello D, Porta M, et al.: Imaging Analysis of the International Tourette Syndrome Deep Brain Stimulation Registry and Database (abstract). Mov Disord. 2018; 33(suppl 2).

Reference Source

Khalsa SS, Adolphs R, Cameron OG, et al: Interoception and Mental Health: A Roadmap. Biol Psychiatry Cogn Neurosci Neuroimaging. 2018; 3(6): 501-513. PubMed Abstract | Publisher Full Text | Free Full Text

Kim S, Greene D, Bihun EC, et al.: Transient tics aren't: Outcome of recentonset tic disorder at one year. OSF Preprints. 2018a. Publisher Full Text

Kim S, Greene DJ, Bihun EC, et al: Provisional Tic Disorder is not so transient. Sci Rep. 2019; 9(1): 3951

PubMed Abstract | Publisher Full Text | Free Full Text

Kim S, Jackson SR, Groom M, et al:: Visuomotor learning and unlearning in children and adolescents with tourette syndrome. Cortex. 2018b; 109: 50-59. PubMed Abstract | Publisher Full Text

Kronenbuerger $\mathrm{M}$, Belenghi $\mathrm{P}$, llgner $\mathrm{J}$, et al.: Olfactory functioning in adults with Tourette syndrome. PLoS One. 2018; 13(6): e0197598. PubMed Abstract | Publisher Full Text | Free Full Text

Köhler-Forsberg O, Petersen L, Gasse C, et al.: A Nationwide Study in Denmark of the Association Between Treated Infections and the Subsequent Risk of Treated Mental Disorders in Children and Adolescents. JAMA Psychiatry. 2019; 76(3): 271-279.

PubMed Abstract | Publisher Full Text | Free Full Text

Lennington JB, Coppola G, Kataoka-Sasaki Y, et al.: Transcriptome Analysis of the Human Striatum in Tourette Syndrome. Biol Psychiatry. 2016; 79(5): 372-382. PubMed Abstract | Publisher Full Text | Free Full Text

Lowe TL, Capriotti MR, McBurnett K: Long-Term Follow-up of Patients with Tourette's Syndrome. Mov Disord Clin Pract. 2019; 6(1): 40-45.

PubMed Abstract | Publisher Full Text | Free Full Text

Mahone EM, Puts NA, Edden RAE, et al:: GABA and glutamate in children with Tourette syndrome: A ${ }^{1} \mathrm{H}$ MR spectroscopy study at $7 \mathrm{~T}$. Psychiatry Res 
Neuroimaging. 2018; 273: 46-53.

PubMed Abstract | Publisher Full Text | Free Full Text

Maia TV, Conceição VA: Dopaminergic Disturbances in Tourette Syndrome: An Integrative Account. Biol Psychiatry. 2018; 84(5): 332-344.

PubMed Abstract | Publisher Full Text

Mancini C, Cardona F, Baglioni V, et al.: Inhibition is impaired in children with obsessive-compulsive symptoms but not in those with tics. Mov Disord. 2018 33(6): 950-959.

PubMed Abstract | Publisher Full Text

Martinez-Ramirez D, Jimenez-Shahed J, Leckman JF, et al:: Efficacy and Safety of Deep Brain Stimulation in Tourette Syndrome: The International Tourette Syndrome Deep Brain Stimulation Public Database and Registry. JAMA Neurol. 2018; 75(3): 353-359.

PubMed Abstract | Publisher Full Text | Free Full Text

Mataix-Cols D, Frans E, Pérez-Vigil A, et al:: A total-population multigenerational family clustering study of autoimmune diseases in obsessive-compulsive disorder and Tourette's/chronic tic disorders. Mol Psychiatry. 2018; 23(7): 1652-1658. PubMed Abstract | Publisher Full Tex

Mufford MS, Cheung J, Jahanshad N, et al:: Concordance Of Genetic Variation That Increases Risk For Tourette Syndrome And That Influences Its Underlying Neurocircuitry. bioRxiv. 2018.

Publisher Full Text

Nespoli E, Rizzo F, Boeckers T, et al.: Altered dopaminergic regulation of the dorsal striatum is able to induce tic-like movements in juvenile rats. PLoS One. 2018; 13(4): e0196515.

PubMed Abstract | Publisher Full Text | Free Full Text

Neurocrine Biosciences Inc: Neurocrine Biosciences Announces Topline Data from Phase Ilb T-Force GOLD Study Demonstrating Valbenazine Did Not Meet Primary Endpoint in Pediatric Patients with Tourette Syndrome. 2018. Reference Source

Nissen JB, Kaergaard M, Laursen L, et al:: Combined habit reversal training and exposure response prevention in a group setting compared to individual training: a randomized controlled clinical trial. Eur Child Adolesc Psychiatry. 2019; 28(1): 57-68.

PubMed Abstract | Publisher Full Text | Free Full Text

Petruo V, Bodmer B, Brandt VC, et al:: Altered perception-action binding modulates inhibitory control in Gilles de la Tourette syndrome. J Child Psychol Psychiatry. 2018.

PubMed Abstract | Publisher Full Tex

Poh W, Payne JM, Gulenc A, et al:: Chronic tic disorders in children with ADHD. Arch Dis Child. 2018; 103(9): 847-852.

PubMed Abstract | Publisher Full Tex

Pérez-Vigil A, Fernández de la Cruz L, Brander G, et al:: Association of Tourette Syndrome and Chronic Tic Disorders With Objective Indicators of Educationa Attainment: A Population-Based Sibling Comparison Study. JAMA Neurol. 2018; 75(9): 1098-1105.

PubMed Abstract | Publisher Full Text | Free Full Text

Rae CL, Larsson DEO, Garfinkel SN, et al:: Dimensions of interoception predict premonitory urges and tic severity in Tourette syndrome. Psychiatry Res. 2019; 271: $469-475$.

PubMed Abstract | Publisher Full Text

Rae CL, Polyanska L, Gould van Praag CD, et al.: Face perception enhances insula and motor network reactivity in Tourette syndrome. Brain. 2018; 141(11): 3249-3261.

PubMed Abstract | Publisher Full Text | Free Full Text

Ricketts EJ, Rozenman M, Choy C, et al:: 4.37 Nights of Sufficient Sleep in Children With Tourette's Disorder: Findings From the National Survey of Children's Health. J Am Acad Child Adolesc Psychiatry. 2017; 56(10): S241. Publisher Full Text

Rizzo R, Pellico A, Silvestri PR, et al:: A Randomized Controlled Trial Comparing Behavioral, Educational, and Pharmacological Treatments in Youths With Chronic Tic Disorder or Tourette Syndrome. Front Psychiatry. 2018; 9: 100. PubMed Abstract | Publisher Full Text | Free Full Text

Robbins H: Summary of results from a study conducted by researchers at the University of Hertfordshire, exploring the eating and dietary behaviours in children with TS. 2018

Reference Source

Shephard E, Groom MJ, Jackson GM: Implicit sequence learning in young people with Tourette syndrome with and without co-occurring attention-deficit/ hyperactivity disorder. J Neuropsychol. 2018.

PubMed Abstract | Publisher Full Text

Sigurdsson HP, Pépés SE, Jackson GM, et al:: Alterations in the microstructure of white matter in children and adolescents with Tourette syndrome measured using tract-based spatial statistics and probabilistic tractography. Cortex.

2018; 104: 75-89.

PubMed Abstract | Publisher Full Text | Free Full Text

Silvestri PR, Baglioni V, Cardona F, et al:: Self-concept and self-esteem in patients with chronic tic disorders: A systematic literature review. Eur $J$ Paediatr Neurol. 2018; 22(5): 749-756.

PubMed Abstract | Publisher Full Text

Smeets AYJM, Duits AA, Horstkötter D, et al.: Ethics of Deep Brain Stimulation in Adolescent Patients with Refractory Tourette Syndrome: a Systematic Review and Two Case Discussions. Neuroethics. 2018; 11(2): 143-155.

PubMed Abstract | Publisher Full Text | Free Full Text

Smith B, Rogers SL, Blissett J, et al.: The role of sensory sensitivity in predicting food selectivity and food preferences in children with Tourette syndrome.

Appetite. 2019; 135: 131-136.

PubMed Abstract | Publisher Full Text

Stenner MP, Baumgaertel C, Heinze HJ, et al.: Intact automatic motor inhibition in patients with tourette syndrome. Mov Disord. 2018; 33(11): 1800-1804.

PubMed Abstract | Publisher Full Text

Stern JS: Tourette's syndrome and its borderland. Pract Neurol. 2018; 18(4): 262-270

PubMed Abstract | Publisher Full Tex

Taylor C, Mitchell-Blake T, Kharod A, et al:: Predictors of adaptive functioning in children with tourette syndrome attending a specialist clinic. Arch Dis Child. 2018 .

Reference Source

Wang S, Mandell JD, Kumar Y, et al.: De Novo Sequence and Copy Number Variants Are Strongly Associated with Tourette Disorder and Implicate Cell Polarity in Pathogenesis. Cell Rep. 2018; 24(13): 3441-3454.e12.

PubMed Abstract | Publisher Full Text | Free Full Text

Weingarden H, Scahill L, Hoeppner S, et al.: Self-esteem in adults with Tourette syndrome and chronic tic disorders: The roles of tic severity, treatment, and comorbidity. Compr Psychiatry. 2018; 84: 95-100.

PubMed Abstract | Publisher Full Text | Free Full Text

Willsey AJ, Fernandez TV, Yu D, et al.: De Novo Coding Variants Are Strongly Associated with Tourette Disorder. Neuron. 2017; 94(3): 486-499.e9. PubMed Abstract | Publisher Full Text | Free Full Text

Wu MS, Rozenman M, Peris TS, et al:: Comparing OCD-Affected Youth With and Without Religious Symptoms: Clinical Profiles and Treatment Response. Compr Psychiatry. 2018; 86: 47-53.

PubMed Abstract | Publisher Full Text | Free Full Text

Yates R, Edwards $\mathrm{K}$, King J, et al:: Habit reversal training and educational group treatments for children with Tourette syndrome: A preliminary randomised controlled trial. Behav Res Ther. 2016; 80: 43-50.

PubMed Abstract | Publisher Full Text

Yu D, Sul JH, Tsetsos F, et al:: Interrogating the Genetic Determinants of Tourette's Syndrome and Other Tic Disorders Through Genome-Wide Association Studies. Am J Psychiatry. 2019; 176(3): 217-227. PubMed Abstract | Publisher Full Text

van de Griendt JMTM, van Dijk MK, Verdellen CWJ, et al: The effect of shorter exposure versus prolonged exposure on treatment outcome in Tourette syndrome and chronic tic disorders - an open trial. Int J Psychiatry Clin Pract. 2018; 22(4): 262-267.

PubMed Abstract | Publisher Full Tex

van der Salm SMA, van der Meer JN, Cath DC, et al:: Distinctive tics suppression network in Gilles de la Tourette syndrome distinguished from suppression of natural urges using multimodal imaging. Neuroimage Clin. 2018; 20: 783-792

PubMed Abstract | Publisher Full Text | Free Full Text 


\section{Open Peer Review}

\section{Current Peer Review Status:}

\section{Version 1}

Reviewer Report 02 September 2019

https://doi.org/10.5256/f1000research.21424.r52244

(C) 2019 Lavoie M. This is an open access peer review report distributed under the terms of the Creative Commons Attribution License, which permits unrestricted use, distribution, and reproduction in any medium, provided the original work is properly cited.

\section{Marc Lavoie}

1 Département de neurosciences, Université de Montréal, Montreal, QC, Canada

2 Department of Psychiatry and Addiction, Université de Montréal, Montréal, QC, Canada

This is a well selected review that covers most of the essential 2018 works on Tourette syndrome. One area that will probably have a big impact in the future, is the ability to predict which neurocognitive variables represents good predictors of clinical evolution in TS.

Electrophysiological measures were useful to predict outcome, following a psychological intervention, in other psychiatric disorders, such as anxiety disorders, depression and obsessivecompulsory disorder (Krause et al., 2015; Burkhouse et al., 2016) ${ }^{1,2}$, but has yet to be tested in TS. One article did just that last year. I suggest to add an article by Morand-Beaulieu and colleagues $(2018)^{3}$ that suggest that electrophysiological markers could offers new predictors for therapeutic outcome in TS and CTD patients with its high temporal precision to follow the stream of fast cognitive and motor processes. Morand-Beaulieu et al (2018) suggested that motor-related and slow cortical potentials could constitute electrophysiological markers of TS.

These measures are related to SMA and basal ganglia functioning which is pretty consistent with neuroimaging and electrophysiological studies already reported in the current manuscript. I believe that this article could fit well in the "clinical and neuropsychological studies" section or perhaps in the 'psychological intervention' section if you decide to integrate it.

\section{References}

1. Krause D, Folkerts M, Karch S, Keeser D, et al.: Prediction of Treatment Outcome in Patients with Obsessive-Compulsive Disorder with Low-Resolution Brain Electromagnetic Tomography: A Prospective EEG Study.Front Psychol. 2015; 6: 1993 PubMed Abstract | Publisher Full Text 2. Burkhouse KL, Kujawa A, Kennedy AE, Shankman SA, et al.: NEURAL REACTIVITY TO REWARD AS A PREDICTOR OF COGNITIVE BEHAVIORAL THERAPY RESPONSE IN ANXIETY AND DEPRESSION. Depress Anxiety. 2016; 33 (4): 281-8 PubMed Abstract | Publisher Full Text 3. Morand-Beaulieu S, O'Connor KP, Blanchet PJ, Lavoie ME: Electrophysiological predictors of cognitive-behavioral therapy outcome in tic disorders.J Psychiatr Res. 105: 113-122 PubMed Abstract | Publisher Full Text

\section{Is the topic of the review discussed comprehensively in the context of the current}




\author{
literature? \\ Yes \\ Are all factual statements correct and adequately supported by citations? \\ Yes \\ Is the review written in accessible language? \\ Yes \\ Are the conclusions drawn appropriate in the context of the current research literature? \\ Yes \\ Competing Interests: No competing interests were disclosed. \\ Reviewer Expertise: Neuropsychology; Cognitive electrophysiology; Clinical psychology \\ I confirm that I have read this submission and believe that I have an appropriate level of \\ expertise to confirm that it is of an acceptable scientific standard.
}

Reviewer Report 15 July 2019

https://doi.org/10.5256/f1000research.21424.r50717

(C) 2019 de la Cruz L. This is an open access peer review report distributed under the terms of the Creative Commons Attribution License, which permits unrestricted use, distribution, and reproduction in any medium, provided the original work is properly cited.

\title{
Lorena Fernández de la Cruz
}

Department of Clinical Neuroscience, Centre for Psychiatry Research, Karolinska Institutet, Stockholm, Sweden

This is yet again a good summary of the most relevant TS literature published in the past year (2018). The text is useful for researchers and clinicians in the TS and related fields, and in my opinion constitutes a nice educational piece. The included papers are overall well chosen and summarised. I only have a few minor comments, listed below.

The authors have included in their review the paper by Wu et al. (2018) ${ }^{1}$, which refers to the clinical characteristics and treatment outcomes of children and adolescents with OCD with and without religious symptoms. This article concludes that the presence of religious symptoms is not associated with OCD treatment outcomes. Based on this, the authors of the current review affirm that this suggests that scrupulosity and similar symptoms in children with TS can be expected to improve just as much as other OCD symptoms with appropriate treatment. While this may be true, I think this conclusion is long stretched based on the Wu et al. (2018) data, which actually does not refer to TS or tics at all. I therefore suggest to remove this paper from the review.

When the authors mention the treatment study by Andrén et al. $(2019)^{2}$, I think it is important to 
mention that the percentages in the parenthesis in the sentence "Patients improved substantially (mean 75\% with ERP, 55\% with HRT)" actually refer to treatment responders, and not the percentage of patients that simply improved.

Last sentence of the "Etiology" section: "the association is interesting and deserves follow-up". This reads weird to me and I suggest to change the wording to "deserves to be further explored" or similar.

Please check the manuscript for typos; there are quite a few. Some of them are listed below: "Phenomenology and natural history" section; "Sensory phenomena and premonitory urges", third paragraph: the verb is missing in the sentence "alterations in olfactory phenomena ARE likely to occur..."

"Phenomenology and natural history" section; "Other", second paragraph: "in A French university clinic" instead of "in French university clinic."

"Pathophysiology" section; "Neuroimaging studies", third paragraph: write "functional" in lower case.

"Treatment" section; “Neurosurgery": a registry for deep brain stimulation (DBS) FOR Tourette syndrome..."

Note that the acronym ASD appears before it is spelled out, two paragraphs later (page 3).

\section{References}

1. Wu MS, Rozenman M, Peris TS, O'Neill J, et al.: Comparing OCD-affected youth with and without religious symptoms: Clinical profiles and treatment response.Compr Psychiatry. 86: 47-53 PubMed Abstract | Publisher Full Text

2. Andrén P, Aspvall K, Fernández de la Cruz L, Wiktor P, et al.: Therapist-guided and parent-guided internet-delivered behaviour therapy for paediatric Tourette's disorder: a pilot randomised controlled trial with long-term follow-up.BMJ Open. 2019; 9 (2): e024685 PubMed Abstract |

Publisher Full Text

\section{Is the topic of the review discussed comprehensively in the context of the current} literature?

Yes

Are all factual statements correct and adequately supported by citations? Partly

Is the review written in accessible language?

Yes

Are the conclusions drawn appropriate in the context of the current research literature? Yes 
Competing Interests: I receive royalties for contributing articles to UpToDate, Wolters Kluwer Health.

Reviewer Expertise: Obsessive-compulsive disorder, Tourette's syndrome, body dysmorphic disorder, hoarding disorder, psychiatric epidemiology

I confirm that I have read this submission and believe that I have an appropriate level of expertise to confirm that it is of an acceptable scientific standard.

\section{Comments on this article}

\section{Version 1}

Author Response ( F1000Research Advisory Board Member) 03 Sep 2019

Kevin J Black, Washington University School of Medicine, St. Louis, USA

We thank Drs. Fernández de la Cruz and Lavoie for their thoughtful and constructive comments.

Competing Interests: No competing interests were disclosed.

The benefits of publishing with F1000Research:

- Your article is published within days, with no editorial bias

- You can publish traditional articles, null/negative results, case reports, data notes and more

- The peer review process is transparent and collaborative

- Your article is indexed in PubMed after passing peer review

- Dedicated customer support at every stage

For pre-submission enquiries, contact research@f1000.com 